\title{
Outpatient Parenteral Antimicrobial Therapy (OPAT) in the Kingdom of Bahrain: Efficacy, Patient Satisfaction and Cost Effectiveness
}

\author{
Ahmed Al Ansari ${ }^{*}$, , Samah Al Alawi ${ }^{2}$, Manaf Al Qahtani ${ }^{3}$ and Abdulla Darwish ${ }^{3}$ \\ ${ }^{1}$ Department of General Surgery, Bahrain Defense Force Hospital, Riffa, Kingdom of Bahrain \\ ${ }^{2}$ Department of General Practice, Bahrain Defense Force Hospital, Riffa, Kingdom of Bahrain \\ ${ }^{3}$ Department of Pathology, Bahrain Defense Force Hospital, Riffa, Kingdom of Bahrain
}

\begin{abstract}
Outpatient parenteral antimicrobial therapy (OPAT) is an alternative method to deliver intravenous antimicrobial agents to patients requiring parenteral therapy without an overnight hospital stay. The aim of this study was to review the OPAT services, to explore patient satisfaction with the services provided, and to determine cost effectiveness. A retrospective review for the raw data collected in the OPAT clinic between February 2012 and January 2013 was included. Patients' variables including age, sex, type of infection, and service costs were analyzed with descriptive statistics. Each patient's eligibility was assessed by an infectious disease physician (ID), and a family physician. Patient's satisfaction was measured by a modified short version patient satisfaction questionnaire. Cost was calculated for each patient in the OPAT clinic and compared to the actual cost if the same patient was admitted and treated in the hospital. During the last 12 months, 101 patients, 92 adults, and nine children were treated in our OPAT clinic. Half $(50 \%)$ of the patients were referred from general practitioner services and our emergency department. Ceftriaxone was the most frequently used antibiotic, prescribed to $76 \%$ of the patients. Successful cure was achieved in 97 treated patients. Patients were highly satisfied with the OPAT service with the mean rating of $4.41 \mathrm{SD} \pm 0.31$. Cost was reduced from $\$ 75$, 000 to $\$ 30,000$ over one year. This retrospective study suggested that OPAT service is safe and potentially a cost saving approach for the health care system. OPAT service is acceptable and well tolerated among patients receiving intravenous antimicrobial agents.
\end{abstract}

Keywords: Outpatient parenteral antimicrobial therapy (OPAT), Bahrain, antibiotics, infections.

\section{INTRODUCTION}

Outpatient parenteral antimicrobial therapy (OPAT) is frequently used to facilitate early discharge from hospitals, and subsequently to reduce the risk of health care associated infections and to increase patient satisfaction [1]. In the recent years, the use of OPAT services has increased in various countries due to evidence that supports its clinical justification and cost effectiveness [2]. The key to success in the OPAT services is providing treatment equivalent to inpatient services and decreasing hospital stay, while improving patient satisfaction [3]. To do so, appropriate patient selection can be the main factor that contributes effectively to success and safety in the treatment of a number of conditions treated in the OPAT clinic, including endocarditis, cystic fibrosis, soft tissue infection, and osteomyelitis [4-6].

Although outpatient parenteral antimicrobial therapy (OPAT) started in 1974 in the United States [7], this practice is considered relatively new to the Middle East. OPAT services started in the Kingdom of Bahrain in February 2012, with the primary aim of reducing patient hospital stay, increasing patient's satisfaction, lowering admission cost,

*Address correspondence to this author at the Department of General Surgery, Bahrain Defence Force Hospital, P.O Box 28347, Riffa, Kingdom of Bahrain; Tel: 00973 17776060; E-mail: drahmedalansari@gmail.com and providing patient-centered care. In our OPAT clinic, patients attend an outpatient clinic where therapy is administered by trained health care workers. The model that involves visiting patients at their home has not yet been implemented.

Therefore, the main purpose of the present study was to review our OPAT services, to explore efficacy and patient satisfaction with the services provided by the OPAT clinic, and to determine cost effectiveness.

\section{METHODS}

A retrospective analysis for the collected data regarding all OPAT patients between February 2012 and January 2013 was completed at the Bahrain Defense Force Hospital in the Kingdom of Bahrain. The Bahrain defense force hospital is a military hospital consisting of 450 beds, 322 physicians and dentists, and 1,072 nurses and practical nurses. The yearly inpatients' admission is around 21,462 patients, and there are more than 347,025 consultations carried out in the clinics. In November 2000, it became the first hospital in Bahrain to have the majority of its departments certified by the International Standards Organization (ISO9001-2000). The Bahrain defense force hospital achieved a pinnacle in its provision of care with a commitment to "Quality, Safety, and Efficiency" when the Australian Council on Healthcare Standards (ACHS) granted the hospital full accreditation, with 5 extensive Achievements in major areas of care. The 
hospital provides services for all the military people and their families. In addition, the hospital accepts any emergency case from the military and civilian population. The OPAT clinic was the first clinic in the Kingdom of Bahrain; it consisted of 5 beds and was located in the outpatient general practice clinic, situated close to the emergency department. Patients were referred by inpatient and outpatient hospital services and assessed by the OPAT team for eligibility. The OPAT team consists of an infectious disease (ID) physician, chief resident family physician, specialist nurse, and a pharmacist.

Patients referred to the OPAT service were assessed by either an ID physician or chief resident family physician for eligibility. The assessment process was based on international guidelines and the guidelines of the Infectious Diseases Society of America (IDSA) [8]. The referring physicians and the ID physician were responsible for determining the antibiotic type, dosage, duration, and type of intravenous administration in line with our current local antibiogram reports. Patients in the OPAT clinic were monitored (either daily or three times a week) clinically and/or by blood work, depending on the case, by the chief resident family physician or a specialist nurse available at the clinic. The OPAT clinic service differs from inpatient care that it provides the same care and treatment that the patient required, without the need for an overnight hospital stay. Patient demographics including age, sex, types of infection, co-morbidities, and type of antibiotics, were retrieved from an Excel spreadsheet designed for this study.

Cost in the OPAT clinic was determined by calculating the patients' costs when treated as an outpatient, and comparing those to the costs of treating them as inpatients while receiving the same care. The inpatient fees were obtained from the billing department.

Patient satisfaction was determined via the short version of a patient satisfaction questionnaire with 18 questions. The survey was modified and translated to Arabic language. Two-way translation was carried out to ensure consistent meaning [9].

The collected data was analyzed using SPSS version 18, and descriptive statistics were conducted. Reliability was examined by Cronbach's Alpha. Content validity was established by blueprint and expert opinion and the construct validity of the instrument was assessed by exploratory factor analysis.

\section{RESULTS}

During the 12 months period from February 2012 to January 2013, 101 patients, 92 adult and 9 pediatric patients were treated at our OPAT clinic. Cases in the OPAT clinic were classified into simple cases requiring short IV therapy (up to 7 days), or complex cases requiring long IV therapy (> 7 days).

Half $(50 \%)$ of the patients were referred from general practitioner services and our emergency department; $25 \%$ were referred by medical services, and $15 \%$ were referred by surgical services. The pediatric and the obstetrics and gynecology departments shared the same percentage of referrals at $4 \%$. The orthopedic department referred around
$2 \%$ of the total cases. The majority of the patients were male $(57 \%)$.

The conditions treated ranged from simple to complicated cases. Overall, ear, nose, and throat (ENT) diseases contributed to $35 \%$ of the total cases. Urinary tract infections, cellulitis, and respiratory tract diseases represented $17 \%, 14 \%$, and $13 \%$, of the cases, respectively. Post-operative wound infections represented $8 \%$ of the total cases. Gastrointestinal tract (GIT) infections, breast, bone, diabetic foot, and central nervous system (CNS) diseases represented the remaining $12 \%$ of the total cases. Comorbidities were reported in 29 patients, including cases with diabetes mellitus, hypertension, obesity, chronic obstructive pulmonary disease (COPD), bronchial asthma, and one case of congenital heart disease.

Ceftriaxone was the most frequently used antibiotic, and it was prescribed in $76 \%$ of the cases. Ceftriaxone was used in ENT cases and other cases as well such as urinary infections, cellulitis, respiratory, and diabetic foot. Meropenem and Vancomycin were the second and third most common antibiotics used in the OPAT clinic, representing $6 \%$ and $5 \%$ of the total patients, respectively. Meropenem was used in extended spectrum Beta-lactamse (ESBL) pseudomonas Spp urinary tract infections, while Vancomycin was primarily used in complicated methicillin-resistance staphylococcus aureus (MRSA) skin and soft tissue infections. Less frequently used antibiotics were Tazocin, Cefotaxime, Ceftazidime, Penicillin G, Streptomycin, Amakacin, and Ertapenam.

The total cost for the OPAT clinic treatment over the last 10 months was approximately $\$ 30,000$. However, if the same patients had been admitted to the hospital, they would have cost the hospital approximately $\$ 75,000$. Furthermore, if the same group had been admitted to a private ward in the same hospital, the cost would have been $\$ 95,000$. This indicates that the hospital saved $\$ 45,000$ in the last 10 months by using the OPAT service to treat these patients. This suggests that OPAT is potentially a cost saving approach for the health care system given its general shorter duration of therapy in comparison to inpatient treatment. We are analyzing the costing of the approach in detail including opportunity costs and costs associated with adverse events and re-admissions for a separate manuscript. The average duration of treatment ranges from three to 10 days.

Total cure was achieved in 97 treated patients, two patients were readmitted to the hospital, and another two patients were lost to follow-up with the OPAT clinic. Central venous access was not used for all patients. Only 14 patients were on peripherally inserted central catheters (PICC), and the remaining 87 patients used a large caliber peripheral line (Table 1).

Patient satisfaction was examined by the short version of the patient satisfaction questionnaire, consisting of 18 questions. Ware and his colleagues developed the patient satisfaction questionnaire in 1976. Since that time, the questionnaire has been used in different settings and providing valuable information [10]. The survey was modified and translated to Arabic language. Two-way translation was completed to ensure consistent meaning in both languages. Face and content validity were examined by 
Table 1. Patients and Treatment Characteristics in OPAT Clinic

\begin{tabular}{|c|c|}
\hline Number of Patients & 101 \\
\hline Gender & Male $57 \%$, Female $43 \%$ \\
\hline Adults/Pediatric & $92 / 9$ \\
\hline \multicolumn{2}{|l|}{ Referral } \\
\hline General Practitioner and Emergency & $50 \%$ \\
\hline Medical Services & $25 \%$ \\
\hline Surgical Services & $15 \%$ \\
\hline Pediatric departments & $4 \%$ \\
\hline Obstetrics and gynecology & $4 \%$ \\
\hline Orthopedic service & $2 \%$ \\
\hline \multicolumn{2}{|l|}{ Antibiotic Used } \\
\hline Ceftriaxone & $76 \%$ \\
\hline Meropenum & $6 \%$ \\
\hline Vancomycin & $5 \%$ \\
\hline Tazocin & $3 \%$ \\
\hline Cefotaxime & $3 \%$ \\
\hline Ceftazidime & $2 \%$ \\
\hline Penicillin G & $2 \%$ \\
\hline Streptomycin & $1 \%$ \\
\hline Amakacin & $1 \%$ \\
\hline Ertapenam & $1 \%$ \\
\hline \multicolumn{2}{|l|}{ Central Venous Access } \\
\hline peripherally inserted central catheters (PICC) & $14 \%$ \\
\hline large caliber peripheral line & $87 \%$ \\
\hline \multicolumn{2}{|l|}{ Cost } \\
\hline Total Cost & $30,000 \$$ \\
\hline Hospital Admission & $75,000 \$$ \\
\hline Private Room in the Hospital & $95,000 \$$ \\
\hline Saving over 10 months & $45,000 \$$ \\
\hline \multicolumn{2}{|l|}{ Conditions Treated } \\
\hline ear, nose, and throat diseases & $35 \%$ \\
\hline Urinary tract infection & $17 \%$ \\
\hline Cellulites & $14 \%$ \\
\hline Respiratory tract infection & $13 \%$ \\
\hline Post-operative wound infection & $8 \%$ \\
\hline Gastrointestinal tract infection & $3 \%$ \\
\hline Breast & $3 \%$ \\
\hline Osteomyelitis & $3 \%$ \\
\hline Diabetic Foot & $2 \%$ \\
\hline Meningitis & $2 \%$ \\
\hline \multicolumn{2}{|l|}{ Co-Morbidities } \\
\hline Diabetes Mellitus & $9.9 \%$ \\
\hline Hypertension & $7.9 \%$ \\
\hline Obesity & $4.9 \%$ \\
\hline COPD & $3.0 \%$ \\
\hline Bronchial Asthma & $2.0 \%$ \\
\hline Congenital heart diseases & $1.0 \%$ \\
\hline Patient satisfaction Mean & $4.41 \mathrm{SD} \pm 0.31$ \\
\hline
\end{tabular}

expert opinion and a blueprint. The questionnaire was distributed to all patients on the last day of treatment.
Patients were asked to complete the questionnaire anonymously, and to place the completed form in a closed box in the OPAT clinic. The questionnaire was rated on a 5points Likert scale ranging from $1=$ strongly agree to $5=$ strongly disagree. The response rate was $96.9 \%$, supporting the feasibility of the instrument. Patients were highly satisfied with the OPAT service with the mean rating of 4.41 $\mathrm{SD} \pm 0.31$.

Instrument reliability refers to the consistency of the score obtained using that specific instrument. Reliability was examined by Cronbach's Alpha, which was 0.81 and indicates good reliability. Content validity of the instrument is partly a matter of determining if the content that the instrument contains is an adequate sample of the domain of content it is supposed to present. Content validity was established by constructing a table of specification where the course content and extent of understanding are identified and the number of questions chosen reflects the emphasis placed on the topics and the overall course objectives. This is frequently called a "blueprint".

In addition, we addressed face and content validity by sending the instrument to an expert in the field to review the content and format of the instrument and judge whether or not it is appropriate. Construct validity is an on-going process. The construct validity was tested to ensure that the same factors will be derived by using this questionnaire in the OPAT clinic. The instrument's construct validity is the psychological aspect of the content. Exploratory factor analysis was conducted to identify the factors assessed using this questionnaire. A factor analysis is a multivariate technique for identifying whether the correlations between a set of observed variables stem from their relationship to one or more latent variables in the data, each of which takes the form of a linear model. Factor analysis is a technique for identifying groups or clusters of variables. In other words, it is a tool or method to uncover and quantify latent variables.

The first step in factor analysis is to look at the correlation matrix of the responses to the questions [11]. Factor loadings can define (as the regression coefficient of a variable) the linear model that describes a latent variable or factor in the factor analysis. By examining the component matrix for each item, the loading that has the highest absolute values suggests the factor or component to which that item belongs. The higher the correlation between two items (or questions), the more likely it is that they belong to the same latent variable or factor. Items that are not correlated do not belong to the same latent variables or factors. By examining the correlation matrix, we can see the magnitude of the correlation coefficient, as they give some indication as to which items belong together within a latent variable [12].

To obtain how many factor or latent variables are involved we have to do the extraction methods. Any component with eigenvalues greater than 1 can be considered a factor. With the method of forcing in the exploratory factor analysis to three factors, however, three factors were identified to represent $54.6 \%$ of the variance. These factors were assessing: physician competency and interpersonal relationship; medical care; and time-related issue. 
Listed below are some things people say about health care. Please read each one carefully, keeping in mind the health care you are receiving now. (If you have not received care recently, think about what you would expect if you needed care today.) We are interested in your feelings, good and bad, about the health care you have received. The phrase "health care provider" includes physicians, physician assistants and nurse practitioners.

How strongly do you AGREE or DISAGREE with each of the following statements? (Circle One Number on Each Line)

\begin{tabular}{|c|c|c|c|c|c|}
\hline & $\begin{array}{c}\text { Strongly } \\
\text { Agree }\end{array}$ & Agree & Uncertain & Disagree & $\begin{array}{c}\text { Strongly } \\
\text { Disagree }\end{array}$ \\
\hline $\begin{array}{l}\text { 1. Health care providers are good about explaining the } \\
\text { reason for medical tests. }\end{array}$ & 1 & 2 & 3 & 4 & 5 \\
\hline $\begin{array}{l}\text { 2. I think my health care provider's office has everything } \\
\text { needed to provide complete medical care. }\end{array}$ & 1 & 2 & 3 & 4 & 5 \\
\hline 3. The health care I have been receiving is just about perfect. & 1 & 2 & 3 & 4 & 5 \\
\hline $\begin{array}{l}\text { 4. Sometimes health care providers make me wonder if their } \\
\text { diagnosis is correct. }\end{array}$ & 1 & 2 & 3 & 4 & 5 \\
\hline $\begin{array}{l}\text { 5. I feel confident that I can get the health care I need without } \\
\text { being set back financially. }\end{array}$ & 1 & 2 & 3 & 4 & 5 \\
\hline $\begin{array}{l}\text { 6. When I go for health care, the provider is careful to check } \\
\text { everything when treating and examining me. }\end{array}$ & 1 & 2 & 3 & 4 & 5 \\
\hline 7. I have to pay for more of my health care than I can afford. & 1 & 2 & 3 & 4 & 5 \\
\hline 8. I have easy access to the medical specialists I need. & 1 & 2 & 3 & 4 & 5 \\
\hline $\begin{array}{l}\text { 9. Where I get health care, people have to wait too long for } \\
\text { emergency treatment. }\end{array}$ & 1 & 2 & 3 & 4 & 5 \\
\hline $\begin{array}{l}\text { 10. Health care providers act too businesslike and impersonal } \\
\text { toward me. }\end{array}$ & 1 & 2 & 3 & 4 & 5 \\
\hline $\begin{array}{l}\text { 11. My health care provider treats me in a very friendly } \\
\text { and courteous manner. }\end{array}$ & 1 & 2 & 3 & 4 & 5 \\
\hline $\begin{array}{l}\text { 12. Those who provide my health care sometimes hurry too } \\
\text { much when they treat me. }\end{array}$ & 1 & 2 & 3 & 4 & 5 \\
\hline 13. Health care providers sometimes ignore what I tell them. & 1 & 2 & 3 & 4 & 5 \\
\hline $\begin{array}{l}\text { 14. I have some doubts about the ability of the health } \\
\text { care providers who treat me. }\end{array}$ & 1 & 2 & 3 & 4 & 5 \\
\hline $\begin{array}{l}\text { 15. Health care providers usually spend plenty of time } \\
\text { with me. }\end{array}$ & 1 & 2 & 3 & 4 & 5 \\
\hline $\begin{array}{l}\text { 16. I find it hard to get an appointment for health care } \\
\text { right away. }\end{array}$ & 1 & 2 & 3 & 4 & 5 \\
\hline $\begin{array}{l}\text { 17. I am dissatisfied with some things about the health care } \\
\text { I receive. }\end{array}$ & 1 & 2 & 3 & 4 & 5 \\
\hline 18. I am able to get health care whenever I need it. & 1 & 2 & 3 & 4 & 5 \\
\hline
\end{tabular}

Fig. (1). Short-form patient satisfaction questionnaire (PSQ-18).

\section{DISCUSSION}

This OPAT clinic is considered the first service program to be provided in the Kingdom of Bahrain. To our knowledge and after an extensive search, we could not find in the literature similar programs provided anywhere in the Middle East. Some home-based intravenous antibiotic programs are available in some countries in the Arabian Gulf region and they use the home visiting nurse model. Recently in the Kingdom, there has been more emphasis on increasing care in the community, by reducing length of stay for inpatients and, where possible, avoiding admission altogether.

In this study, Ceftriaxone was the most frequent antibiotic prescribed, and the overall cure rate of infections was high. Our results correspond with previous studies from OPAT services in other countries [13,14]. Chapman et al. reported that ceftriaxone was used in $80.5 \%$ of patients treated. However, it was mainly used for more serious infections such as soft tissue sepsis. Cure rates exceeding $90 \%$ in other OPAT services, were also previously reported $[15,16]$.

Patient satisfaction was achieved by the OPAT service. Patient satisfaction was examined by a short version of the patient satisfaction questionnaire (Fig. 1). Patients were highly satisfied with the OPAT service with a mean rating of 4.41 SD \pm 0.31 . Reliability was 0.81 , which indicates good reliability. Construct validity showed three factor solutions representing $54.6 \%$ of the variance. In our literature review, we did not identify any previous study that has assessed 
Table 2. Duration of IV Therapy with Different Cases

\begin{tabular}{|l|l|}
$\begin{array}{l}\text { Simple short IV therapy (up to } 7 \text { days) For Inpatient or Outpatient } \\
\text { Referred directly To OPAT clinic for appointment and assessment }\end{array}$ & $\begin{array}{l}\text { Complex Long IV Therapy (> 7 days) For admitted patients consult ID } \\
\text { Physician and for clinic patients refer to ID clinic (q Sunday \& } \\
\text { Monday) with notification }\end{array}$ \\
\hline PICC is only indicated if therapy needed for $>\mathbf{3}$ days & PICC Line is indicated for all cases \\
\hline Cellulitis & Vascular Graft Infections \\
\hline Suppurative Tonsillitis /Otitis & Osteomylitis \\
\hline Staphylococcus aureus bacteremia & Arthroplasty infection \\
\hline Diabetic foot (No osteomyelitis) & Brain abscess or other CNS infection \\
\hline Simple Pyelonephritis & Septic arthritis \\
\hline Other indications based on ID assessment & Endocarditis \\
\hline & Other indications required longer therapy based on ID assessment \\
\hline
\end{tabular}

patient satisfaction using a similar questionnaire in other OPAT clinics.

This study and other similar works provide further evidence of the safety and clinical efficacy of OPAT in the treatment of different conditions, including cellulitis, osteomyelitis, simple pyelonephritis, diabetic foot, and endocarditis [13]. Duration of treatments varied from short therapy (up to 7 days) with some conditions, to long therapy (more than 7 days) with other diseases. (Table 2)

However, it is very likely that in future this mode of treatment delivery will be used frequently future in the Kingdom of Bahrain, and beyond the delivery of parenteral antibiotics for selected patients. In this OPAT service, we adhered to a clear treatment protocol and policy for delivering safe and effective antimicrobial therapy by both nurses and treating physicians.

The success rate at the end of intravenous therapy was high and the rate of complications was low, with a readmission rate during intravenous therapy of $2 \%$. The main goal in our OPAT clinic was to select and to treat patients who require intravenous antibiotic therapy and who do not require any admission to the hospital. This study provides further evidence of the safety and clinical efficacy of OPAT services. Thus, we cautiously suggest that this method of treatment delivery may be implemented at other centers in the Kingdom of Bahrain. This service used the outpatient ('infusion centre') only and did not implement home therapy, which requires the visiting nurse model.

\section{CONCLUSION}

In summary, this study showed that the OPAT service model used in our hospital is safe and clinically effective, with low rates of complications/readmissions and high levels of patient satisfaction.

\section{CONFLICT OF INTEREST}

The authors confirm that this article content has no conflict of interest.

\section{ACKNOWLEDGEMENTS}

To Maj. General (Prof.) Khalid Bin Ali Al Khalifa the Director of Royal Medical Services for his support to start the OPAT service in the Bahrain Defense Force hospital.

\section{REFERENCES}

[1] Barr DA, Semple L, Seaton RA. Outpatient parenteral antimicrobial therapy (OPAT) in a teaching hospital-based practice: a retrospective cohort study describing experience and evolution over 10 years. Int J Antimirob Agents 2012; 39: 407-13.

[2] Chapman Ann L, Seaton RA, Cooper MA, et al. Good Practice recommendations for outpatient parenteral antimicrobial therapy (OPAT) in adults in the UK: a consensus statement. J Antimicrob Chemother 2012; 67: 1053-62.

[3] Fisher DA, Kurup A, Lye D, et al. Outpatient parenteral antibiotic therapy in Singapore. Int J Antimicrob Agents 2006; 28: 545-50.

[4] Grayson ML, Silvers J, Turnidge J. Home intravenous antibiotic therapy. A safe and effective alternative to inpatient care. Med J Aust 1995; 162: 249-53.

[5] Upton A, Ellis-Pegler RB, Woodhouse A. Outpatient parenteral antimicrobial therapy (OPAT): a review of experience at Auckland Hospital. N Z Med J 2004; 117(1200): U1020.

[6] Esposito S. Treatment of lower respiratory tract infections in Italy: the role of outpatient parenteral antibiotic therapy. Chemotherapy 2001; 47: 33-40.

[7] Rucker RW, Harrison GM. Outpatient intravenous medications in the management of cystic fibrosis. Pediatrics 1974; 54: 358-60.

[8] Available at: http://www.idsociety.org/IDSA_Practice_Guidelines/

[9] Beaton D, Bombardier C, Guillemin F, Ferraz MB. Guidelines for the process of cross-cultural adaptation of self-report measures. Spine 2000; 25: 3186-191.

[10] Ware J, Snyder M, Wright W. Development and validation of scales to measure patient satisfaction with medical care services. Review of literature. Overview of methods, and results regarding construction of scales (NTIS Publication No. PB 288-329). Springfield, VA: National Technical Information Service 1976.

[11] Anderson TW, Rubin H. Statistical inference in factor analysis. In: Neyman J, Ed. Proceedings of the Third Berkeley Symposium on Mathematical Statistics and Probability. Berkeley: University of California Press 1956; pp. 111-159.

[12] Costello AB, Osborne JW. Best practices in exploratory factor analysis: Four recommendations for getting the most from your analysis. Pract Assess Res Eval 2005; 10: 77-82.

[13] Nathwani D. The management of skin and soft tissue infections: Outpatient parenteral antibiotic therapy in the United Kingdom. Chemotherapy 2001; 47: 17-23. 
[14] Chambers S, Gallagher K, Metealf S, Pithie A. Home intravenous antimicrobial service twelve months experience in Christchurch. $\mathrm{N}$ Z Med J 2002; 115: 216-8.

[15] Duncon C, Barr DA, Seaton RA. Outpatient Parenteral antimicrobial therapy with ceftriaxone, a review. Int J Clin Pharm 2012; 34: 410-17.
[16] Chapman AL, Dixon S, Andrews D, Lillie PJ, Bazaz R, Patchett JD. Clinical efficacy and cost-effectiveness of outpatient parenteral antibiotic therapy (OPAT): a UK perspective. J Antimicrob Chemother 2009; 64: 1316-24.

Received: March 6, 2013

Revised: May 9, 2013

Accepted: May 9, 2013

(C) Al Ansari et al.; Licensee Bentham Open.

This is an open access article licensed under the terms of the Creative Commons Attribution Non-Commercial License (http: //creativecommons.org/licenses/by$\mathrm{nc} / 3.0 /$ ) which permits unrestricted, non-commercial use, distribution and reproduction in any medium, provided the work is properly cited. 